\title{
Morte súbita em caprino por ruptura de aneurisma em aorta abdominal
}

Erick Platiní Ferreira Souto, Maria Talita Soares Frade, Robério Gomes Olinda, Glauco José Nogueira de Galiza, Eldine Gomes Miranda Neto, Antônio Flávio Medeiros Dantas

Programa de Pós-Graduação em Medicina Veterinária, Hospital Veterinário, Centro de Saúde e Tecnologia Rural, Universidade Federal de Campina Grande (UFCG), Patos, PB, Brasil

*Autor correspondente

e-mail: erickplatini@gmail.com

\section{Resumo}

Aneurisma é uma dilatação localizada e permanente da parede de um vaso arterial. Os mecanismos ligados à sua formação estão relacionados a processos degenerativos ou inflamatórios. A principal consequência é a ruptura do vaso, que pode cursar com hemorragia intensa, choque hipovolêmico e morte súbita. 0 presente trabalho descreve um caso de morte súbita em caprino por ruptura de aneurisma em aorta abdominal. Foi encaminhada para necropsia no Laboratório de Patologia Animal da UFCG, em dezembro de 2010, uma cabra adulta, sem raça definida, proveniente da zona rural do município de Patos, Paraíba, que morreu subitamente sem apresentar sinais clínicos prévios, segundo o proprietário. No exame externo do cadáver, observou-se estado corporal regular e mucosas pálidas. Na necropsia, havia grande quantidade de coágulos de sangue na cavidade abdominal, recobrindo as vísceras, e múltiplos abscessos nos rins, pulmões, linfonodos, baço e adrenal. Ao corte, esses abscessos apresentavam conteúdo caseoso branco-amarelado e eram revestidos por cápsula brancacenta. Na aorta abdominal, próximo ao rim direito, havia aumento de volume saculiforme com aproximadamente $15 \mathrm{~cm}$ de diâmetro e parcial ruptura longitudinal. Após a abertura, verificou-se sangue coagulado dissecando as camadas do vaso e presença de grande coágulo intraluminal aderido à íntima. Microscopicamente, observou-se perda da íntima do vaso e substituição por trombos de fibrina e neutrófilos degenerados, que se projetavam ao lúmen. Na camada média do vaso, havia múltiplos microabscessos com área central de necrose e formação de lamelas concêntricas, associados a agregados multifocais de bactérias cocobacilares basofílicas e hemorragia dissecante. Adjacentes às áreas de hemorragia, verificou-se difuso infiltrado inflamatório constituído por neutrófilos e macrófagos, tecido de granulação e edema moderado distendendo as fibras. 0 diagnóstico foi estabelecido com base nos dados epidemiológicos, clínicos e anatomopatológicos. Na região Nordeste do Brasil, a principal 
causa de abscessos em linfonodos e vísceras de caprinos e ovinos adultos é a linfadenite caseosa, causada pelo Corynebacterium pseudotuberculosis. Essa doença foi previamente associada à formação e ruptura de aneurisma aórtico em caprino pela presença de abscesso na parede do vaso. Nesse caso, puderam ser visualizados múltiplos microabscessos na parede do vaso, que provavelmente desencadearam a formação e ruptura do aneurisma, com consequente hemorragia intensa, choque hipovolêmico e morte súbita do animal. Portanto, sugere-se que as alterações inflamatórias, provavelmente decorrentes da infecção pelo Corynebacterium pseudotuberculosis, favoreceram a formação e ruptura do aneurisma nesse caso, devendo essa condição ser considerada no diagnóstico diferencial de morte súbita em caprinos. 